Mr. Saniter's paper, describing a new method for the analysis of chrome and ferro-chromium, was the last read at this sitting. This is a further extension of Mr. Stead's modification of Dr. Clarke's process, and has the great advantage of reducing the time occupied in the analysis.

On the afternoon of this day there were several excursions, the chief of which was to Worcester, where the works of the Royal Porcelain Company were inspected. Another party visited the Round Oak Iron and Steel Works, while others proceeded to the glass works, fireclay works, small arms factories, and to other works in and around Birmingham. In the evening there was a very successful reception and entertainment in the Edgbaston Botanical Gardens.

The final sitting of the meeting was on Thursday of last week, when a paper by Mr. Henry Wiggin, on nickel steel, was first taken. In this contribution the advantages of nickel steel as a constructive material were brought forward; its great tensile strength combined with excessive ductility being dwelt upon. Another advantage possessed is freedom from corrosion, as compared with ordinary steel. Instances were given of the nickel steel containing $3 \frac{1}{4}$ per cent. of nickel, which had a tensile strength fully 30 per cent. higher than ordinary steel, and an elastic limit at least 75 per cent. higher. The author does not give any details in regard to cost, which is naturally higher than that of ordinary steel; but speaking upon the subject generally, he was of opinion that the additional price that would have to be charged would generally be more than compensated for by insreased efficiency. In the discussion, Mr. W. Beardmore, of Glasgow, said he had been making large quantities of nickel steel for the last two years. This was for armour-plates, but he was now preparing a series of tests to submit to Lloyd's with a view to introducing the material for marine purposes. Mr. Jeremiah Head, who had lately visited America, said that at the works of $\mathrm{Mr}$. Carnegie he had seen large quantities of nickel steel produced at a cost, he was told, of about $£ 7$ a ton ; but there natural gas of great richness was available. Mr. Thompson, of New York, who had been largely engaged in the manufacture of nickel steel, said that in America 50,000 to 75,000 tons of this material had been produced during the last three years. A German chemist had found that with an alloy of I5 per cent. of nickel almost a new metal was made having a tensile strength of $244,000 \mathrm{lbs}$. to the square inch, and an elastic limit as high in proportion. He estimated that to build a large battleship of nickel steel would add but 2 per cent. to her cost, whilst the efficiency would be doubled. Mr. Thomas Turner afterwards pointed out that nickel steel was supposed to have a wide range of extension and contraction with variations of temperature, so that if a ship went to the polar regions it might become even feet shorter in its length.

Mr. Smith-Casson's paper, on small cast ingots, was next read. The author claims to have got very good results by casting ingots together from the bottom. This was the last paper read at the meeting.

Thursday afternoon was devoted to an excursion to Stratford on-Avon, whilst on the following day, Friday, an excursion was made to Kenilworth and to Warwick, where members and their friends were entertained at the Castle by Lord and Lady Warwick.

\section{THE SPECTRUM OF HELIUM.'}

IN the Chemical News for March 29 last (vol: 1xxi. p. I5I), I published the results of measurements of the wave-lengths of the more prominent lines seen in the spectrum of the gas from cleveite, now identified with helium. The gas had been given to me by the discoverer, Prof. Ramsay; and being from the first batch prepared, it contained other gases as impurities, such as nitrogen and aqueous vapour, both of which gave spectra interfering with the purity of the true helium spectrum. I have since, thanks to the kindness of Profs. Ramsay and J. Norman Lockyer, had an opportunity of examining samples of helium from different minerals and of considerable purity as far as known contamination is concerned. These samples of gas were sealed in tubes of various kinds and exhausted to the most luminous point for spectrum observations. In most cases no internal electrodes were used, but the rarefied gas was illuminated solely by induction, metallic terminals being attached to the outside

$$
1 \text { From the Chemical Neats, August } 23 \text {. }
$$

of the tube. ${ }^{1}$ For photographic purposes a quartz window was attached to the end of the tube, so that the spectrum of the gas could be taken " end on."

My examinations have chiefly been made on five samples of gas.

( I) A sample from Prof. Ramsay in March last. Prepared from clèveite.

(2) A sample from Prof. Ramsay in May last. Prepared from a specimen of uraninite sent to him by Prof. Hillebrand. Gas obtained by means of sulphuric acid; purified by sparking.

(3) A sample from Prof. Ramsay in June last. Prepared from bröggerite.

(4) A sample from Prof. Lockyer in July last. Prepared by a process of fractional distillation from a sample of bröggerite sent by Prof. Brögger.

(5) A sample of gas from Prof. Ramsay, "Helium Purissimum." This was obtained from mixed sources, and had been purified to the highest possible point.

In the following table the first four samples of gas will be called :--(I) "Clèveite, R."; (2) "Uraninite, R" ; (3) "Bröggerite, R" ; and (4) "Bröggerite, L." Only the strongest of the lines, and those about which I have no doubt, are given. The wave-lengths are on Rowland's scale.

The photographs were taken on plates bent to the proper curvature for bringing the whole spectrum in accurate focus at the same time. The spectrum given by a spark between an alloy of equal atoms of mercury, cadmium, zinc, and tin, was photographed at the same time on the plate, partially overlapping the helium spectrum; suitable lines of these metals were used as standards. The measurements were taken by means of a special micrometer reading approximately to the $\mathrm{I} / \mathrm{roO}, 000 \mathrm{th}$ inch, and with accuracy to the $\mathrm{I} / \mathrm{IO}, \mathrm{oooth}$ of an inch. The calculations were performed according to Sir George Stokes's formula, supplemented by an additional formula kindly supplied by Sir George Stokes, giving a correction to be applied to the approximate wave-lengths given by the first formula, and greatly increasing the accuracy of the results.

Wave-

length. Intensity. A red line, seen in all the samples of gas. $7065^{\circ} 5 \quad 5 \quad$ A red line, seen in all the samples of gas.
Young gives a chromospheric line at 7065.5 .

$6678 \cdot 1 \quad 8$ A red line, seen in all the samples of gas. Thalén gives a line at 6677 , and Lockyer at 6678 . Young gives a chromospheric line at $6678 \cdot 3$.

5876.0 The characteristic yellow line of helium, seen in all the samples of gas. Thalén makes it $5875^{\circ} 9$, and Rowland $5875^{\circ} 98$. Young gives a chromospheric line at 5876 .

$5062 \cdot 15 \quad 3$ A yellow-green line, only seen in "Helium

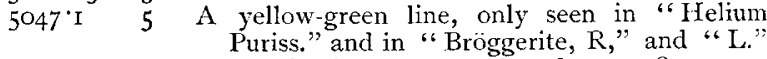
Thalén gives the wave-length as 5048 .

5015.97 A green line seen in all the samples of gas. Thalén gives the wave-length 5016 . Young gives a chromospheric line at $5^{\circ} 5^{\circ} 9^{\circ}$.

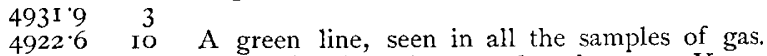
Thalén gives the wave-length 4922 . Young gives a chromospheric line at $4922 \cdot 3$.

$4870^{\circ} 7$ A green line, only seen in "Uraninite, R." Young gives a chromospheric line at $4870^{\circ} 4$.

4847.37 A green line, only seen in "Uraninite, R." Young gives a chromospheric line at $4848 \cdot 7$.

4805.69 A green line, only seen in "Uraninite, R." Young gives a chromospheric line at $4805^{\circ} 25$.

$4764^{\circ} 42$ There is a hydrogen line at $4764^{\circ} \mathrm{O}$.

$4735^{\circ}$ I Io A very strong greenish blue line, only seen in "Uraninite, R."

4713.49 A blue line, seen in all the samples of gas. Thalén's measurement is 4713.5 . Young gives a chromospheric line at $4713 \%$.

4658.58 A blue line, only seen in "Uraninite, R."

$4579^{\circ}$ I 3 A faint blue line, seen in "Uraninite, R." Lockyer gives a line at 4580 , from certain minerals. I can see no traces of it in the gas from Bröggerite. A hydrogen line occurs at $4580 \cdot 1$.

1 Journal of the Institution of Electrical Engineers, part $9 \mathrm{r}$, vol. $\mathrm{xx}$. 1 Journal of the Institution of Electrical Engineers, part 91, vol. xx.,
Inaugural Address by the President, William Crookes, F.R.S., Jan. 15. I89r.

NO. I 348 , YOL. 52 ] 
Wave-

length. Intensity.

$4559^{\circ} 4 \quad 2$ Young gives a chromospheric line at $455^{\circ} 9$.

$4544^{\prime} \mathrm{I}$

$45^{2} 0^{\circ} 9$

5

A faint blue line, seen in "Uraninite, R." Lockyer gives a line at 4522 , seen in the gas from some minerals. Young gives a chromospheric line at $45^{22} 2^{\circ}$. It is absent in the gas from Bröggerite.

45II 4 5 A blue line, seen in "Uraninite, R," but not in the others. It is coincident with the strong head of a carbon band in the $\mathrm{CO}_{2}$ and $\mathrm{Cy}$ spectrum.

$4497 \cdot 8 \quad 2 \quad$ There is a hydrogen line at $4498 \cdot 75$

$447 \mathrm{I}^{\circ} 5$ Io A very strong blue line, having a fainter line on each side, forming a close triplet. It is a prominent line in all the samples of gas examined. Young gives the wave-length 4471.8 for a line in the chromosphere, and Lockyer gives $447 \mathrm{I}$ for a line in gas from Bröggerite.

4435'7 9 Seen in " Helium Puriss",

$4437^{\circ}$ I I Young gives a chromospheric line at $4437^{\circ} 2$.

These two lines form a close pair. I can only

4428 . IO see them in "Uraninite, R." No trace of

$4424^{\circ}$ them can be seen in the gases from other sources. Young gives chromospheric lines at $4426 \cdot 6$ and $4425 \cdot 6$.

$4399^{\circ}$ Io A strong line, only seen in "Uraninite, R." Absent in the gas from the other sources. Lockyer gives a line at 4398 in gas from certain minerals. Young gives a chromospheric line at $4398^{\circ} 9$.

$43^{86} 36$ Seen in all the samples of gas. Young gives a chromospheric line at $43^{\circ} 5^{\circ}$.

$4378.8 \quad 8$ These two lines form a pair seen in "Uraninite,

437 I.o 8 R," but entirely absent in the others.

$4348^{\circ} 4$ Io Seen in "Uraninite, R." Lockyer finds a line at 4347 in the gas from certain minerals.

$4333^{\circ} 9$ Io Probably a very close double line. Seen in " Uraninite, R," and "Clèveite, R." Not seen in the other samples. Lockyer gives a line in the gas from certain minerals at 4338 .

4298.7 6 Only seen in "Uraninite, R." Young gives a chromospheric line at $4298 \cdot 5$.

$428 \mathrm{I} \cdot 3 \quad 5 \quad$ Only seen in "Uraninite, R."

$4271^{\circ} \mathrm{O} \quad 5$ Only seen in "Uraninite, R." The strong hea of a nitrogen band occurs close to this line.

4258.8 7 Seen in all the samples of gas.

4227. I 5 Only seen in "Uraninite, R." Young gives a chromospheric line at $4226 \cdot 89$

$4198 \cdot 6$

$4189^{\circ} 9$

$4 \mathrm{I} 8 \mathrm{I} \cdot 5$

$4178 \cdot 1$

These three lines form a prominent group in 9 "Uraninite, R," they are very faint in

9 " Clèveite, R," and in Bröggerite, L," but are not seen in " Bröggerite, R."

An extremely faint line. Lockyer gives a line at $4 \mathrm{I} 77$, seen in the gas from certain minerals, and Young gives a chromospheric line at $4179^{\circ} 5$.

4I69.4 6 Seen in "Helium Puriss."

4I57.6 8 A strong line in "Uraninite, R," very faint in "Bröggerite, R," and "L," not seen in "Clèveite, R."

4143.9 7 Strong in "Clèveite, R," in " Helium Puriss.," and in "Bröggerite, L." It is faint in "Uraninite, $\mathrm{R}$," and not seen in "Bröggerite, R." Lockyer gives a line at 4145 in gas from certain minerals.

4I2I'3 7 Present in all the gases except "Clèveite, R."

4044.3 9 Present in "Uraninite, R," and "Clèveite, R." Absent in the others.

4026. These lines form a very close pair, seen in all

4024 . I5 6 6 $\begin{aligned} & \text { the samples of gas, except "Bröggerite, R." } \\ & \text { Lockyer finds a line in Bröggerite gas at }\end{aligned}$ $4026 \cdot 5$.

4012.9 7 Seen in all the samples of gas.

400927 Seen in "Helium Puriss."

$3964^{-8}$ Io The centre line of a dense triplet. Only seen in "Clèveite, R," in Helium Puriss.," and " Bröggerite, L." Hale gives a chromospheric line at 3964 .

NO. 1348, VOL, 52$]$
Wave

length. Intensity.

$3962 \cdot 3 \quad 4$ Seen in all the samples of gas.

$3948^{\circ} 2$ IO Very strong in "Uraninite, R," very faint in "Clèveite, R," and not seen in the others. Lockyer finds a line in gas from Bröggerite at 3947. There is an eclipse line at the same wave-length.

3925.8 2 Seen in "Helium Puriss."

2 Seen in " Helium Puris,"

3913.24 Only seen in "Uraninite, R," and " Helium Puriss." Hale gives a chromospheric line at 3913.5 .

A very strong triplet, seen in all the samples of gas. Lockyer finds a line having a wave-

3888.5 Io length 3889 in gas from Bröggerite. Hale

$3885^{\circ} 9 \quad 9 \quad$ gives a chromospheric line at 3888.73 . There is a strong hydrogen line at 3889. I 5

3874.6 6 Only seen in "Uraninite, R."

3867'7 8 Seen in "Helium Puriss."

3819.4 Io Seen in all the samples of gas. Deslandres gives a chromospheric line at 3819.8 .

3800.6 4 Seen in " Helium Puriss.'

$3732 \cdot 5 \quad 5$ Seen in "Helium Puriss." Hale gives a chromospheric line at 3733.3

$3705^{\circ} 6$ Seen in all the samples of gas. Deslandres gives a chromospheric line at $3705^{\circ} 9$.

3642 $0 \quad 8$ Only seen in "Uraninite, R."

$3633.3 \quad 8$ Seen in "Helium Puriss."

$3627.8 \quad 5$ Only seen in "Uraninite, R."

3613.7 9 Seen in "Helium Puriss."

$3587^{\circ} \circ \quad 5 \quad$ Seen in "Helium Puriss."

$3447 \cdot 8 \quad 8$ Seen in "Helium Puriss."

3353.85 Seen in " Helium Puriss."

$3^{247} 52$ Seen in "Helium Puriss."

3187.3 Io The centre line of a close triplet. Very faint in "Clèveite, R," and "Uraninite, R," and strong in "Helium Puriss." and in "Brög. gerite, L." It is not seen in "Bröggerite, R."

$2944^{\circ} 98$ A prominent line, only seen in "Helium Puriss." and in "Bröggerite, L."

2536.58 Seen in "Helium Puriss." A mercury line occurs at $2536 \cdot 72$.

2479. 4 Seen in "I Helium Puriss."

2446.4 2 Seen in "Helium Puriss."

2419.82 Seen in "Helium Puriss."

Some of the more refrangible lines may possibly be due to the presence of a carbon compound with the helium. To photograph them, a long exposure, extending over several hours, is necessary. The quartz window has to be cemented to the glass with an organic cement, and the long-continued action of the powerful induction current on the organic matter decomposes it, and fills the more refrangible end of the spectrum with lines and bands in which some of the flutings of hydrocarbon, cyanogen, and carbonic anhydride are to be distinguished.

There is a great difference in the relative intensities of the same lines in the gas from different minerals. Besides the case mentioned by Prof. Kayser of the yellow and green lines, 5876 and 50I6, which vary in strength to such a degree as to render it highly probable that they represent two different elements, I have found many similar cases of lines which are relatively faint or absent in gas from one source and strong in that from another source.

Noticing only the strongest lines, which. I have called "Intensity 10," "9," or " 8 ," and taking no account of them when present in traces in other minerals, the following appear to be special to the gas from uraninite :-

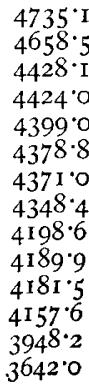


The following strong lines are present in all the samples of gas :-

$7065 \cdot 5$
$6678 \cdot 1$
$5876 \cdot 0$
$5015 \cdot 9$
$4922 \cdot 6$
$4713 \cdot 4$
$4471 \cdot 5$
$4386 \cdot 3$
$4258 \cdot 8$
$4012 \cdot 9$
$3962 \cdot 3$
$3890 \cdot 5$
$3888 \cdot 5$
$3885 \cdot 9$
$3819 \cdot 4$
$3705 \cdot 4$

The distribution assigned to some of the lines in the above tables is subject to correction. The intensities are deduced from an examination of photographs, taken with very varied exposures; some having been exposed long enough to bring out the fainter lines, and some a short time to give details of structure in the stronger lines. Unless all the photographs have been exposed for the same time, there is a liability of the relative intensities of lines in one picture not being the same as those in another picture. Judgment is needed in deciding whether a line is to have an intensity of 7 or 8 assigned to it ; and as in the tables I have not included lines below intensity 8 , it might happen that another series of photographs with independent measurements of intensities would in some degree alter the above arrangement.

In the following table I have given a list of lines which are probably identical with lines observed in the chromosphere and prominences :-

\begin{tabular}{|c|c|c|c|c|c|c|}
\hline \multirow{3}{*}{$\begin{array}{l}\text { Wave-lengths } \\
\text { observed of } \\
\text { helium. } \\
7065^{\circ} \cdot 5 \\
6678 \cdot \mathbf{I}\end{array}$} & & \multicolumn{3}{|c|}{ Intensities. } & \multicolumn{2}{|c|}{$\begin{array}{l}\text { Wave-lengths of } \\
\text { chromospheric lines, } 1 \\
\text { Rowland's scale. }\end{array}$} \\
\hline & & $\ldots$ & IO & $\ldots$ & $\ldots$ & $7065 \cdot 5$ \\
\hline & $\ldots$ & $\ldots$ & Io & $\ldots$ & $\ldots$ & $6678 \cdot 3$ \\
\hline 5876.0 & $\ldots$ & $\cdots$ & 30 &.. & $\ldots$ & 5876.0 \\
\hline 5015.6 & $\ldots$ & $\ldots$ & 6 & $\ldots$ & $\ldots$ & $5015 \cdot 9$ \\
\hline $4922 \cdot 6$ & $\ldots$ & $\ldots$ & IO & $\cdots$ & $\ldots$ & $4922 \cdot 3$ \\
\hline $4870 \cdot 6$ & $\ldots$ & $\ldots$ & 7 & $\ldots$ & $\ldots$ & $4870 \cdot 4$ \\
\hline $4847 \cdot 3$ & $\ldots$ & $\ldots$ & 7 & $\ldots$ & $\ldots$ & $4848 \cdot 7$ \\
\hline 48056 & $\ldots$ & $\cdots$ & 9 & $\ldots$ & $\cdots$ & $4805^{2} 25$ \\
\hline $47 \times 34$ & $\ldots$ & $\ldots$ & 9 & $\ldots$ & $\ldots$ & 4713.4 \\
\hline 4559.4 & $\ldots$ & $\ldots$ & 2 & $\ldots$ & $\ldots$ & $455^{8} \cdot 9$ \\
\hline $45^{20} \cdot 9$ & $\ldots$ & $\ldots$ & 3 & $\ldots$ & $\ldots$ & $4522 \cdot 9$ \\
\hline $4471 \cdot 5$ & $\ldots$ & $\ldots$ & Io & $\ldots$ & $\ldots$ & $447 \mathrm{I} \cdot 8$ \\
\hline $4437^{\circ} \mathrm{I}$ & $\ldots$ & $\ldots$ & I & $\ldots$ & $\ldots$ & $4437^{\circ} 2$ \\
\hline $4428 \cdot 1$ & $\ldots$ & $\ldots$ & 10 & $\ldots$ & $\ldots$ & $4426 \cdot 6$ \\
\hline $4424^{\circ} \mathrm{O}$ & $\ldots$ & $\cdots$ & IO & $\ldots$ & $\ldots$ & $4425 \cdot 6$ \\
\hline $4399^{\circ}$ & $\ldots$ & $\ldots$ & IO & $\ldots$ & $\ldots$ & $4398 \cdot 9$ \\
\hline $43^{86 \cdot 3}$ & $\ldots$ & $\ldots$ & 6 & $\cdots$ & $\cdots$ & $4385 \cdot 4$ \\
\hline $4298 \cdot 7$ & $\ldots$ & $\ldots$ & 6 & $\cdots$ & $\cdots$ & $\begin{array}{l}4305 \cdot 4 \\
4298 \cdot \frac{5}{5}\end{array}$ \\
\hline $4227^{\circ} \mathrm{I}$ & $\cdots$ & $\cdots$ & 5 & $\begin{array}{l}\cdots \\
\cdots\end{array}$ & $\cdots$ & $\begin{array}{l}4290 \\
4226 \cdot 89\end{array}$ \\
\hline $4178 \cdot 1$ & $\ldots$ & $\ldots$ & I & $\ldots$ & $\ldots$ & $4179 \cdot 5$ \\
\hline $3964 \cdot 8$ & $\ldots$ & $\ldots$ & 10 & $\ldots$ & $\ldots$ & $3964^{\circ} \circ \mathrm{H}^{2}$ \\
\hline $3948 \cdot 2$ & $\ldots$ & $\ldots$ & Io & $\cdots$ & $\ldots$ & $3945^{\circ} 2 \mathrm{H}$ \\
\hline 3913.2 & $\cdots$ & $\cdots$ & 4 & $\ldots$ & .. & $39 \mathrm{I} 3.5 \mathrm{HI}$ \\
\hline $3888 \cdot 5$ & $\ldots$ & $\cdots$ & 10 & $\ldots$ & $\ldots$ & $3888.73 \mathrm{H}$ \\
\hline $3^{8} 19 \cdot 4$ & $\cdots$ & $\cdots$ & IO & $\ldots$ & $\ldots$ & $38.9 .8 \mathrm{D}$ \\
\hline $3732 \cdot 5$ & $\cdots$ & $\ldots$ & 5 & $\ldots$ & $\ldots$ & $3733^{\circ} 3$ \\
\hline $3705 \% 4$ & $\cdots$ & $\cdots$ & 6 & $\ldots$ & $\ldots$ & $3705.91)$ \\
\hline & & & & & & CroOkEs. \\
\hline
\end{tabular}

\section{UNIVERSITY AND EDUCATIONAL INTELLIGENCE.}

Mr. Adolph Sutro, well known as the builder of the famous Sutro tunnel on the Comstock lode in Nevada, and now

1 "A Treatise on Astronomical Spectroscopy," by Dr. J. Scheiner, translated by $\mathrm{E}$. B. Frost. Boston, 1894

2 The wave-lengths to which the initials $\mathrm{D}$ and $\mathrm{H}$ are added are wavelengths of lines photographically detected in the spectrum of the chromosphere by Deslandres (D) and Hale $(\mathrm{H})$. Their photographs do not extend beyond wave-length 3630 . Prof. Lockyer (Roy. Soc. Proc. vol. lviii. p. ir6, May 1895 ) has already pointed out fourteen coincidences between the wavelengths of lines in terrestrial helium and in those observed in the chromo. sphere, the eclipse lines, and stellar spectra.

NO. I 348 , VOL. 52$]$
Mayor of San Francisco, has just offered the State University Regents thirteen acres of land within the city limits, on which to erect buildings for the affiliated colleges of the University. In addition to this, he will deed to the Trustee of the city thirteen acres adjoining, as a site for the Sutro library of over 200,000 volumes. The gift is valued at $£ 300,000$, and will be worth $£ 400,000$ when the contemplated improvements are made.

THE Clothworkers' Exhibition, awarded by the Oxford and Cambridge Schools Examination Board to the best candidate in physical science at the examination held for higher certificates, has been gained by T. W. Fagan, Denstone College, Staffordshire. The exhibition, which is of the value of $£_{52}$ ros. a year, is tenable for three years by the holder as a non-collegiate student at either Oxford or Cambridge.

Mr. W. M. Gardner, Assistant Lecturer in Dyeing in the Yorkshire College, Leeds, has been appointed Head Master of the Chemistry and Dyeing Department of the Bradford Technical College.

The Calendar of the Durham College of Science, Newcastle upon Tyne, for the session I $895^{-}-96$ has just been published, and also separate prospectuses of the day and evening classes.

Sir A. RoILIT asked the First Lord of the Treasury on Tuesday whether the Government intended, and when, to propose legislation in pursuance of the report of the Gresham Commission or the University of London. In reply, Mr. Balfour said that legislation will be impossible on the subject in the course of the present Session, and he was unable to say what action will be taken by the Government.

THE operations of the City and Guilds of London Institute are divided broadly into two branches, viz. the educational work of three London Colleges, and of the Technological Examinations. The new edition of the programme of the latter, including regulations for the registration and inspection of classes in technology and manual training, has come to hand. It is more bulky that any of the previous programmes of the examinations, which fact may be taken as an indication that the Institute is growing with the extension of technical education. The technical subjects in which examinations are held now number sixty-three. A practical examination for "electric wiremen" has been added, and a corresponding addition has been made to the syllabus for the preliminary examination in electric lighting. The syllabuses of several other subjects have been modified, and that in wood-work has been rewritten.

THE forty-second Report of the Department of Science and Art has just been received. A noteworthy point shown by the statistics contained in it is the diminution in the number of science schools, classes, and students under instruction, brought about by the abolition of grants for second-class passes in the Elementary Stages of Science subjects. As compared with the previous year, the number of schools in 1894 had decreased by I 52 -from 2754 to 2602 ; the number of pupils had decreased by about I0,000-from 193,431 to I83,120; and the number of classes in different branches of science had decreased by $908-$ from IO,34 I to 9433. This diminution is attributed to the changes in payments on results, "and also probably to the opening of numerous technical classes by the local authorities in different parts of the country, which have drawn away the students from the classes in pure science. The decrease in the number of schools and classes is owing partly to the same cause, and partly to the amalgamation of smaller schools, or to their absorption in the more prosperous and better supported schools in their neigh. bourhood, many classes in which instruction of a very elementary nature only had been given being at the same time closed." A determination has been made of the average ages at which students in the Department's science classes obtained successes in the Elementary and Advanced Stages, It was found that the average age in Day Schools for a student to obtain a first-class elementary success was about I4, and for a second-class Advanced about $15^{\frac{3}{4}}$, while in the evening classes the ages were respectively about 18 and $\mathbf{2 1}$. In addition to statistics, and information as to science instruction and technical education the Report contains the reports of the work of the Geological Survey of the United Kingdom, and of the Committee on Solar Physics. 